\title{
Validity and Reliability of Total Lymphocyte Count as Alternative Biomarker for CD4 Count in the Management of HIV Positive Patients on HAART in Osogbo, Nigeria
}

\author{
B. E. Egbewale1, O. A. Oyedeji², V. O. Mabayoje ${ }^{3,4^{*}}$, M. A. Muhibi, C. A. Akinleyes, \\ A. A. Adejimi1,5 \\ ${ }^{1}$ Department of Community Medicine, College of Health Sciences Osogbo, Ladoke Akintola University \\ of Technology, Ogbomoso, Nigeria \\ ${ }^{2}$ Department of Paediatrics, College of Health Sciences Osogbo, Ladoke Akintola University of Technology, \\ Ogbomoso, Nigeria \\ ${ }^{3}$ Department of Haematology and Blood Transfusion, College of Health Sciences Osogbo, Ladoke Akintola \\ University of Technology, Ogbomoso, Nigeria \\ ${ }^{4}$ Department of Haematology and Blood Transfusion, LAUTECH Teaching Hospital Osogbo, Ladoke Akintola \\ University of Technology, Ogbomoso, Nigeria \\ ${ }^{5}$ Department of Community Medicine, LAUTECH Teaching Hospital, Osogbo, Osun State, Nigeria \\ Email: *tunjimabs@gmail.com
}

Received 9 November 2015; accepted 13 December 2015; published 16 December 2015

Copyright (C) 2015 by authors and Scientific Research Publishing Inc.

This work is licensed under the Creative Commons Attribution International License (CC BY).

http://creativecommons.org/licenses/by/4.0/

C) (i) Open Access

\begin{abstract}
Introduction: To determine the possibility of utilizing total lymphocyte counts (TLC) instead of CD4 counts in the initiation and management of patients with HIV on highly active antiretroviral therapy (HAART). The commencement of HAART CD4 lymphocytes has been employed in the management HIV. However it has been found that determination of CD4 counts is expensive and somewhat laborious to perform in already overburdened healthcare systems especially in the developing countries. Methodology: Five hundred and three (503) consenting patients already on HAART (commenced at CD4 count $<350$ cells/ $\mu$ l) who attended our HIV clinic between February 2014 and February 2015 were enrolled into the study. The patients had already been diagnosed as HIV positive. Kappa statistic was computed as a measure of reliability of TLC. Various cut-off marks for TLC in respect of the CD4 counts were determined in addition to the computation of both sensitivity and specificity. Receiver operating curves (ROC), showing area under the curve indicating agreement in classification, were plotted. Results: Majority of patients were female (73.8\%). Most of the patients were in the age range of 25 - 34 years $(37.2 \%)$. Males were found to
\end{abstract}

${ }^{*}$ Corresponding author.

How to cite this paper: Egbewale, B.E., Oyedeji, O.A., Mabayoje, V.O., Muhibi, M.A., Akinleye, C.A. and Adejimi, A.A. (2015) Validity and Reliability of Total Lymphocyte Count as Alternative Biomarker for CD4 Count in the Management of HIV Positive Patients on HAART in Osogbo, Nigeria. World Journal of AIDS, 5, 313-321. http://dx.doi.org/10.4236/wja.2015.54034 
be significantly older than females $(P<0.05)$. Area under the receiver operating curves $(\mathrm{ROC})$ revealed that 4 out of 10 patients would be missed using total lymphocyte count (TLC) as the indicator for commencement of HAART. A low correlation coefficient and Kappa statistic $r=0.18$, and $K$ $=0.20$ respectively, were observed between TLCs and CD4 counts. Conclusion: Total lymphocyte count is not a suitable alternative to CD4 counts in the management of HIV/AIDS.

\section{Keywords}

HIV, CD4, TLC, HAART

\section{Introduction}

The first clinically observed HIV/AIDS cases were in 1981 in the United States where young homosexual men with impaired immunity were then presenting with Pneumocystis carinni pneumonia (PCP) now jirovechi (PJP) and Kaposi's sarcoma (KS). In 1983, the virus was isolated in a patient with lymphadenopathy [1] and in 1984 the virus was identified in the laboratory by Gallo and his workers for which he received the Nobel Prize [2]. In 1985, the ELISA kit was developed to detect the antibodies to HIV and thus established the ability to diagnose the disease condition. However following this, a diagnosis was initially not of much use to the medical status of the patient, death being only a matter of time. Fortunately with the introduction in 1996 of highly active antiretroviral therapy (HAART) to the management of HIV/AIDS, there has been a considerable improvement in the prognosis of the disease and improved quality of life of affected patients [3]. The disease has evolved from a life-threatening diagnosis to a chronic aliment though, with attendant problems of chronic diseases including side effects of long-term therapy. Notable among these is the metabolic syndrome (lipodystrophy), co-infection with other viruses, hepatitis $C$ virus co-infection being the most notorious [4]. In previous studies carried out among our HIV positive clients, $23.2 \%$ were found to be co-infected with hepatitis C virus [4]. Most populations of HIV patients worldwide are generally thought to be co-infected with hepatitis $\mathrm{C}$ virus with figures as high as a third of whole populations. Ordinarily, about 40 million people worldwide are infected with this virus, and the majority of them are in sub-Saharan Africa, the region where this study is being carried out [5].

Having said this, the use of ARV drugs should be under strict control, monitoring and guidance including maximum adherence in order to obtain optimum effects in the patients [3]. Sub-Saharan Africa is a region of the world where resource limited countries (RLC) lie side by side as neighbors and its people are in a dire need of the benefits of scientific advancements occurring in USA and Europe but at affordable and/or minimal costs.

The gold standard for monitoring patients on HAART is estimation of HIV viral load [6]. However the performance of this is limited by financial considerations especially in resource poor settings such as ours. As a result, there is more reliance on CD4 counts to monitor the effects of HAART. Static or reduced levels of CD4 counts despite being on HAART may indicate resistance and the need to switch to second line therapy. It is well known that the CD4 cells constitute a major portal of entry into the human system by the virus and thus its value would naturally play a vital role in monitoring and managing the disease, especially when the patients are on HAART [7].

Furthermore, determination of CD4 counts at point of entry has been found to increase the probability of reaching patients who are eligible for HAART [8] and this would translate to a reduction of the rate of spread of disease within the society. However, a situation is emerging in which the performance of CD4 lymphocyte counts in lieu of viral load is becoming difficult, due to financial constraints. It has been opined by some that CD4 counts are laborious, expensive and restricted to specialized laboratories [9]. As a result of all the foregoing, it is suggested that alternatives to CD4 counts in monitoring patients on HAART [7] especially in resource limited countries (RLC) be sought.

Suggested alternatives include markers such as Neopterin and $\beta 2$-microglobulin [10] levels which have proven to be significant predictors of AIDS risk in HIV-1 seropositive patients. The predictive value of both parameters is equal to $\mathrm{CD}^{+}$cell counts. Measurement of the parameters is done in serum (neopterin and $\beta 2$-microglobulin) or urine (neopterin) specimens, exposure to which reduces the risk of HIV-1 transmission compared to handling whole-blood samples required for cell counting [11] [12]. Other markers that may be investigated as alternatives include relative lymphocyte count (RLC), absolute eosinophil count, blood Hb, erythro- 
cytes sedimentation rate (ESR), C reactive protein (CRP) and total lymphocyte count [13]. In a study carried out in Kenya a significant linear correlation was found between total lymphocyte count (TLC) and CD4 count. A classification utility of TLC of $1200 / \mathrm{mm}^{3}$ was found to be not useful as cutoff, and a cutoff of $1900 / \mathrm{mm}^{3}$ was recommended to classify patients as either below or above CD4 200/. $\mathrm{mm}^{3}$ as an indicator to commence HAART [14]. Performance of the TLC is a test that can be carried out routinely in the laboratories and does not require special equipment unlike CD4 counts. This would increase access to care and improve health outcomes in people living with HIV/AIDs. However, other studies have suggested that TLC would not be appropriate but may be reliably used in designing algorithms and programs for initiating patient management and follow-up in resource-limited settings [15].

\section{Methodology}

Five hundred and three (503) consenting patients already on HAART (commenced at CD4 count < 350 cells/ $\mu$ l) who attended our HIV clinic between February 2014 and Feb 2015 were enrolled into the study. The patients had already been diagnosed as being HIV positive by screening for the antibody using kits from two different sources, Determine and Unigold. The CD4 cells count was determined by flowcytometry and total lymphocyte count was determined by automated analyzer.

The study region is in Osogbo the capital of Osun state in south west region of Nigeria. The residents are predominantly Yorubas, however there are other tribes including Hausas, Igbos and those of Delta and Edo origin. It is an urban setting with a population of 3,416,959. The weather is typically tropical with periods of heavy rainfall alternating with the dry season.

Inclusion criteria: HIV positive individuals on HAART who voluntarily consented to be included in the study.

Exclusion criteria: Individuals who test negative to HIV and patients not on HAART. Those who declined inclusion into the study were also excluded.

Socio-demographic, clinical and laboratory records including paired TLC s and CD4 counts of 503 HIV positive patients registered in the HIV clinic between February 2014-January 2015 were obtained from record and statistically analyzed. Kappa statistic was computed as a measure of reliability of TLC. Various cut-off marks for TLC in respect of the CD4 counts were determined in addition to the computation of both sensitivity and specificity. Receiver operating curves (ROC) showing area under the curve indicating agreement in classification were plotted.

\section{Results}

A total of 503 participants were included in the study; $73.8 \%$ were female, while $26.2 \%$ were male (Table 1 ). The minimum age observed was 15 years while the maximum was 70 years. The mean age was $38.28 \pm 10.11$. Most of the HIV positive cases were within the age range 25 - 34 years, followed by the 35 - 44 year age range (Table 1). The minimum CD4 count was 5 cells/ $\mu$, while the maximum was 2039 cells/ $\mu$ l. As for the lymphocyte count, the minimum count was 100 cells/ $\mu$ l and the maximum was 6270 cells/ $\mu$ l. The average CD4 count at enrolment was $351 \pm 266.17$ and the average lymphocyte count at enrolment was $1812 \pm 742.63$ (Table 2). Using $<350$ cells $/ \mu$ l CD4 counts as the cutoff, $61.8 \%$ were eligible for HAART of which more than a third were female, however using $<500$ cells/ $\mu$ l as cutoff point $78 \%$ were eligible for HAART. When the cutoff was predicated on the lymphocyte counts, 52.7\% were eligible for HAART.

In our study, male HIV positive patients at enrolment were significantly older than female (Table 2). Although lymphocyte count was higher for male at enrolment, this is not statistically significant as $P>0.05$. However, the CD4 count is statistically significantly higher for the female HIV positive patients compared to their male counterparts $(P<0.05)$. A very low correlation $(r=0.2, P>0.05)$ was observed between the CD4 and lymphocyte counts.

Sensitivity for lymphocyte count at $<1800$ in respect of identifying those who need treatment is about $60 \%$ if compared with CD4 count (CD4 count < 350). Conversely, four patients in every ten would miss initiation of HAART using TLC. The cut-off table shows sensitivity and specificity of each selected lymphocyte count level using the CD4 count of $<350$ cells/ $\mu \mathrm{l}$ and CD4 $<500$ cells/ $\mu$ l as gold standards respectively. In both instances, both sensitivity and specificity of the lymphocyte count as an alternative for determining treatment initiation are very low. Observing the receiver operating curves (ROC) as depicted in Figure 1, lymphocytes counts correctly classified or identified about $60 \%$ of HIV positive patients who needed to start ART. Also in Figure 2 the ROC, 


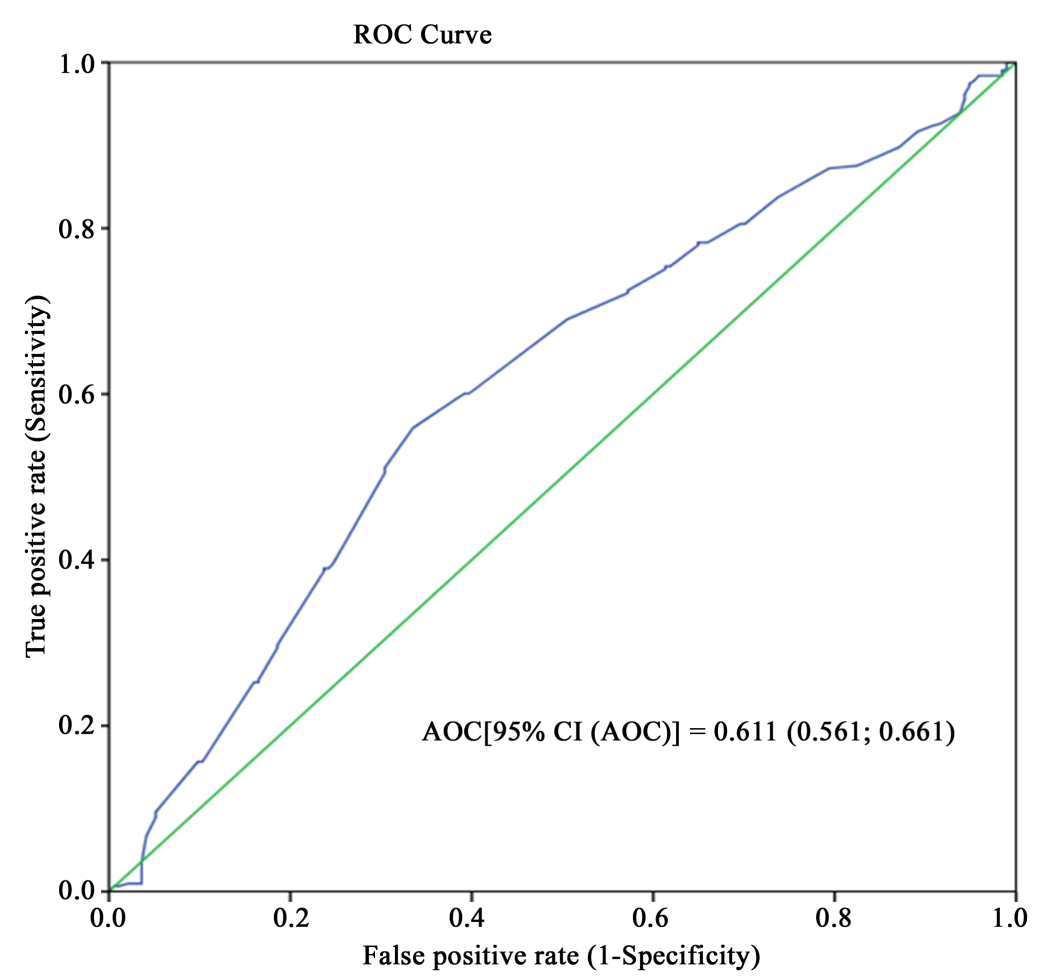

Figure 1. Receiver operating curve showing the sensitivity of lymphocyte counts in determining initiation of ART in relation to the standard of $<350$ CD4 counts.

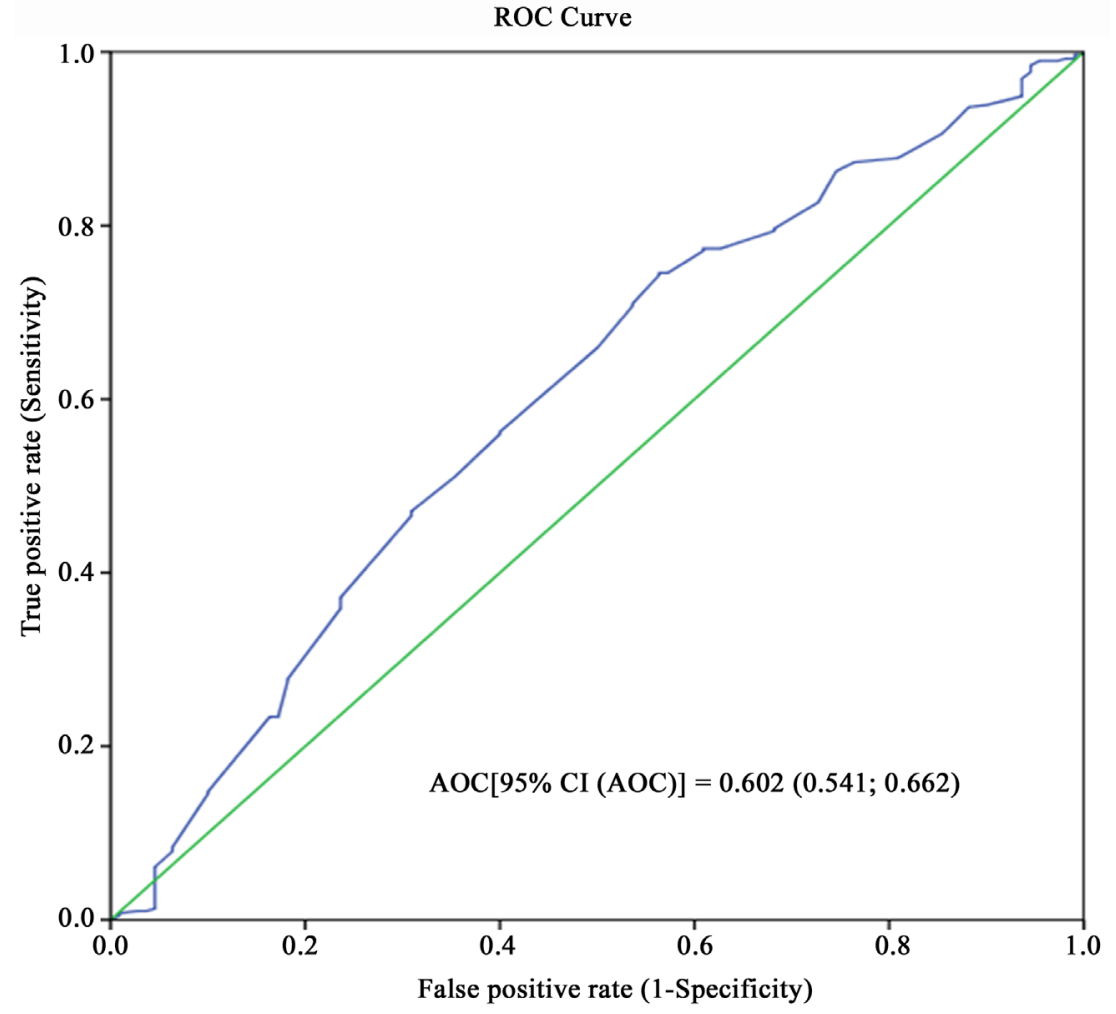

Figure 2. Receiver operating curve showing the sensitivity of lymphocyte counts in determining initiation of ART in relation to the standard of $<500$ CD4 counts. 
Table 1. Socio-demographic characteristics and CD4 counts of HIV positive patients.

Age group

$\begin{array}{lc}15-24 \text { yrs } & 13(2.6) \\ 25-34 \text { yrs } & 187(37.2) \\ 35-44 \text { yrs } & 174(34.6) \\ 45-54 \text { yrs } & 85(16.9) \\ 55-64 \text { yrs } & 37(7.4) \\ 65-74 \text { yrs } & 7(1.4)\end{array}$

Sex

$\begin{array}{cc}\text { Male } & 371(73.8) \\ \text { Female } & 132(26.2)\end{array}$

Educational status

$\begin{array}{cc}\text { Primary } & 18(3.6) \\ \text { Secondary } & 405(80.5) \\ \text { Tertiary } & 80(15.9)\end{array}$

Religion

Islam $215(42.7)$

Christianity $288(57.3)$

CD4 counts guidelines for ART initiation

$\begin{array}{ll}\text { 1. } \mathrm{CD} 4<350 & 311(61.8) \\ \mathrm{CD} 4 \geq 350 & 192(38.2) \\ \text { 2. } \quad \mathrm{CD} 4<500 & 393(78.1) \\ \mathrm{CD} 4 \geq 500 & 110(21.9)\end{array}$

Table 2. Gender difference and selected characteristics of HIV positive patients at enrolment.

\begin{tabular}{cccccccc}
\hline & Sex & $\mathrm{N}$ & Mean & Std. Deviation & Mean Diff. & $t$-test & $P$-value \\
\hline \multirow{2}{*}{ Age } & Male & 132 & 43.22 & 10.23 & & & \\
& Female & 371 & 36.53 & 9.47 & 6.69 & 6.82 & 0.000 \\
\multirow{2}{*}{ Lymphocyte count } & Male & 132 & $1.84 \mathrm{E} 3$ & 759.79 & 45.65 & 0.62 & 0.54 \\
& Female & 371 & $1.80 \mathrm{E} 3$ & 737.10 & & & \\
\multirow{2}{*}{ CD4_count } & Male & 132 & $2.97 \mathrm{E} 2$ & 211.91 & & -2.71 & 0.000 \\
\hline
\end{tabular}

using $<500$ cells/ $\mu$ l as CD 4 count cut-off point reveals as previously observed with CD4 count of <350 cells/ $/$ l, that lymphocytes counts correctly identified about only $60 \%$ of HIV positive patients who needed to start ART. Agreement between lymphocyte counts and CD4 counts in respect of treatment initiation among HIV positive patients in our study population is low (Kappa statistics $=0.2$ ).

\section{Discussion}

HIV/AIDs is a problem that seems to have retained its strong hold in Africa, especially the sub-Saharan region. 
Whereas, Africa has only $10 \%$ of the world's population, $70 \%$ of those infected with HIV reside in Africa. It appears as a problem that isn't going to disappear anytime soon. In this study, there was a total 503 participants and the majority were female. This is similar to findings in other studies [16] [17]. Most of those HIV positive were within the age range 25 - 34 years, followed by the range 35 - 44 years (Table 1). This should not be surprising because of sustained sexual activity among this age group. Over time it has been established that the females are more vulnerable to HIV infection than the male folk [18], so the predominance of the female sex in our study is also in agreement. The reasons for this include biological factors, taking into account the much larger surface areas of the vagina and the cervix compared to areas of the penis through which sexual transmission can occur. It has also been stated globally that females between 15 - 24 years are twice more likely to be infected with HIV than men. There are other social, cultural and economic reasons for which the female sex is more prone. Females are still not yet in a strong position to negotiate for safer sex with their male partners; economically females may need to take up high risk occupations (Prostitution) in cases where they have to feed themselves and their children. There is a dearth of women at levels within the democratic system where important decisions regarding women are taken.

The mean age of the total population in our study is $38.28 \pm 10.11$, while the mean age for females was 36.5 and for males 43.21 (Table 2). In a study carried out in a similar setting, the total mean age was $33 \pm 17$ while that for females was $31 \pm 5.6$ and males $36.5 \pm 8.2$ [17]. Though our patients’ population seems to have higher age groups than that study the male sex populations remained older than the female sex in both studies. In our study, with a mean age difference between the sexes of 6.69 years was found to be statistically significant as $P<$ 0.05 (Table 2). This is similar to finding of Akinola et al. [16].

In the (2010) guidelines, it was recommended that the cut-off point (CD4 count) for the commencement of HAART be elevated from $<200$ cells/ $\mu l$ to $<350$ cells/ $\mu l$ and only recently this cutoff point has been raised to $<500$ cells/ $\mu$ l. Studies in the united states have revealed the value of commencing HAART when CD4 counts are between 350 cells/ $\mu \mathrm{l}$ and 500 cells/ $\mu \mathrm{l}$, there was reduced occurrence of adverse events, reduction of opportunistic infections (including tuberculosis) and prolongation of life of the patients. Commencing HAART at higher CD4 counts reduces progression to AIDs and even death. Various studies have contributed to these findings including ART-CC (cohort collaboration), NA-ACCORD, HIV-Casual cohort and CASCADE. All these studies are remarkable because historically patients were started on HAART when CD4 counts were very low ( $<200$ cells/ $\mu \mathrm{l}$ ) in late stage disease with subsequent poor prognosis. This elevation to $<500$ cells/ $\mu$ l would increase the number of patients on HAART and subsequently reduce the spread of the virus within the society eventually working towards to a possible AIDs free society in Africa and indeed worldwide. This would be using HAART both as treatment and prevention diversifying into increasing the quality of life of the community and public health. Indeed an AIDs free society has recently been predicted by UNIAIDS by the year 2030 .

This increase of cutoff point to $<500$ cells/ $\mu$ l will mean more patients would have to undergo CD4 count estimations. It has already been established that the already overburdened health care system of resource limited countries (RLC) are struggling with the high costs of performing CD4 counts and were searching for cheaper and more accessible means of indicating when to start and monitor patients on HAART. This pressure is even likely to increase with this new cutoff point as the number of cases to be tested would be increased. Several parameters have undergone suitability trials as already mentioned above to determine if they would be acceptable alternatives to the CD4 count. The most popular of these appears to be the TLC.

In a study carried out in British Columbia, Canada it was found that TLC could be used in lieu of CD4 counts in resource poor settings, taking into account prognostic factors such as viral load in resource poor settings such as is ours. In that study, there was emphasis on appropriate validation and caution regards its use. However, studies carried out in Ethiopia were not so optimistic as they revealed low sensitivity and specificity using TLC as a surrogate marker for CD4 counts and discouraged the use of TLC in lieu of CD4 counts. At TLC levels of $<1200$, they obtained a sensitivity and specificity of $41 \%$ and $83.5 \%$ respectively [19] whereas in our study TLC levels (picking the highest and lowest values of TLCs) of 1505 revealed sensitivity of 50\% and of specificity of $69 \%$; and TLC of 2450 revealed a sensitivity of $86 \%$ and specificity of $21.4 \%$ (Table 3 ). This study corroborates what earlier studies have determined in that the correlation between TLCs and CD4 is too low for TLC to be utilized in lieu of CD4 counts. Observing the ROC (Figure 1) with $<350$ as cut off for those who would need HAART 4 out of every 10 patients who need HART would be missed. This is also clearly indicated in the ROC utilizing $<500$ as cut off point (Figure 2). The Spearmans rank correlation $(r=0.2, P>0.05$ ) was low (Table 4) similar to studies performed in the Fiji Islands which also found a relatively low correlation, $\mathrm{r}$ was 0.5 and con- 
Table 3. Lymphocytes count cut-offs for two CD4 count criteria in respect of initiation of HAART.

\begin{tabular}{|c|c|c|c|c|}
\hline \multirow{2}{*}{$\begin{array}{c}\text { Lymphocytes count } \\
\text { Cut-off }\end{array}$} & \multicolumn{2}{|c|}{$\begin{array}{l}\text { With CD4 count of }<350 \text { as eligibility } \\
\text { criterion for initiation of HAART }\end{array}$} & \multicolumn{2}{|c|}{$\begin{array}{l}\text { With CD4 count of }<500 \text { as eligibility } \\
\text { criterion for initiation of HAART }\end{array}$} \\
\hline & Sensitivity & 1-Specificity & Sensitivity & 1-Specificity \\
\hline 1505.0 & 0.507 & 0.307 & 0.466 & 0.309 \\
\hline 1530.0 & 0.511 & 0.307 & 0.468 & 0.309 \\
\hline 1575.0 & 0.514 & 0.307 & 0.471 & 0.309 \\
\hline 1650.0 & 0.563 & 0.339 & 0.511 & 0.355 \\
\hline 1710.0 & 0.605 & 0.396 & 0.560 & 0.400 \\
\hline 1760.0 & 0.605 & 0.401 & 0.562 & 0.400 \\
\hline 1850.0 & 0.695 & 0.510 & 0.659 & 0.500 \\
\hline 1905.0 & 0.727 & 0.578 & 0.707 & 0.536 \\
\hline 1955.0 & 0.730 & 0.578 & 0.710 & 0.536 \\
\hline 2015.0 & 0.756 & 0.620 & 0.743 & 0.564 \\
\hline 2060.0 & 0.759 & 0.620 & 0.746 & 0.564 \\
\hline 2095.0 & 0.759 & 0.625 & 0.746 & 0.573 \\
\hline 2105.0 & 0.785 & 0.656 & 0.771 & 0.609 \\
\hline 2140.0 & 0.788 & 0.656 & 0.774 & 0.609 \\
\hline 2175.0 & 0.788 & 0.661 & 0.774 & 0.618 \\
\hline 2190.0 & 0.788 & 0.667 & 0.774 & 0.627 \\
\hline 2220.0 & 0.810 & 0.703 & 0.794 & 0.682 \\
\hline 2270.0 & 0.810 & 0.708 & 0.796 & 0.682 \\
\hline 2350.0 & 0.842 & 0.745 & 0.827 & 0.727 \\
\hline 2450.0 & 0.868 & 0.786 & 0.863 & 0.745 \\
\hline 2550.0 & 0.878 & 0.802 & 0.873 & 0.764 \\
\hline 2650.0 & 0.904 & 0.880 & 0.878 & 0.809 \\
\hline 2750.0 & 0.923 & 0.901 & 0.906 & 0.855 \\
\hline 2850.0 & 0.929 & 0.917 & 0.926 & 0.882 \\
\hline
\end{tabular}

Table 4. Correlation coefficient between TLC and CD4 counts.

\begin{tabular}{|c|c|c|c|c|}
\hline & & & TLC & CD4_count \\
\hline \multirow{6}{*}{ Spearman’s rho } & \multirow{3}{*}{ TLC } & Correlation coefficient & 1.000 & $0.179^{* *}$ \\
\hline & & Sig. (2-tailed) & . & 0.000 \\
\hline & & $\mathrm{N}$ & 507 & 507 \\
\hline & \multirow{3}{*}{ CD4 count } & Correlation coefficient & $0.179^{* *}$ & 1.000 \\
\hline & & Sig. (2-tailed) & 0.000 & . \\
\hline & & $\mathrm{N}$ & 507 & 507 \\
\hline
\end{tabular}

${ }^{* * *}$ Correlation is significant at the 0.01 level (2-tailed). TLC: Total Lymphocyte Count.

cluded that TLC would not be a suitable alternative [20]. As has been demonstrated, too many HIV positive individuals who need HAART would be deprived of the opportunity most especially in resource poor setting where some centers provide the drugs freely through donor agencies located worldwide. 


\section{Conclusion}

In this study, TLC presents with low agreement with CD4 count and low sensitivity in respect of the decision to initiate HAART. Some HIV positive patients that should be placed on HAART would be denied treatment if TLC is used instead of CD4 count. TLC is not a good alternative for CD4 count in respect of the decision to initiate treatment.

\section{Acknowledgements}

This publication was supported by the co-operative agreement number PS000651-03 from the centers for disease control and prevention (CDC). Its contents are solely the responsibility of the authors and do not necessarily represent the official views of CDC.

\section{References}

[1] Hsiung, G.D. (1987) Perspectives on Retroviruses and the Etiologic Agent of AIDS. Yale Journal of Biology and Medicine, 60, 505-514.

[2] Broder, S. and Gallo, R.C. (1984) A Pathogenic Retrovirus (HTLV-III) Linked to AIDS. New England Journal of Medicine, 311, 1292-1297. http://dx.doi.org/10.1056/NEJM198411153112006

[3] May, M.T. and Ingle, S.M. (2011) Life Expectancy of HIV-Positive Adults: A Review. Sex Health, 8, 526-533. http://dx.doi.org/10.1071/SH11046

[4] Mabayoje, V.O., Muhibi, M.A., Akindele, R.A., Akinleye, C.A., Mabayoje, P.S. and Babatunde, O.S. (2013) Hepatitis C Virus Co-Infection among People Living with HIV/AIDS in a Nigerian Teaching Hospital. HIV and AIDS Review, 12, 102-105. http://dx.doi.org/10.1016/j.hivar.2013.09.003

[5] Venkataramana, K. (2013) A Study of Biological Markers in HIV Disease Progression and Management in the Highly Active Antiretroviral Therapy (HAART) Era. American Journal of Bioscience and Bioengineering, 1, 24-37. http://dx.doi.org/10.11648/j.bio.20130102.11

[6] Hoffman, J., Griensven, J., Colebunders, R. and Keller, M. (2010) The Role of CD 4 Count in HIV Management. HIV Therapy, 4, 27-39. http://dx.doi.org/10.2217/hiv.09.58

[7] Février, M., Dorgham, K. and Rebollo, A. (2011) CD4 ${ }^{+}$T Cell Depletion in Human Immunodeficiency Virus (HIV) Infection: Role of Apoptosis. Viruses, 3, 586-612. http://dx.doi.org/10.3390/v3050586

[8] Wynberg, E., Cooke, G., Shroufi, A., Reid, S.D. and Ford, N. (2014) Impact of Point-of-Care CD4 Testing on Linkage to HIV Care: A Systematic Review. Journal of the International AIDS Society, 17, 18809. http://dx.doi.org/10.7448/IAS.17.1.18809

[9] Vajpayee, M. and Mohan, T. (2011) Current Practices in Laboratory Monitoring of HIV Infection. Indian Journal of Medical Research, 134, 801-822. http://dx.doi.org/10.4103/0971-5916.92627

[10] Hosp, M., Lisse, I.M., Quigley, M., Mwinga, A.M., Godfrey-Faussett, P., Porter, J.D., Luo, N., Pobee, J., Wachter, H., McAdam, K.P. and Fuchs, D. (2000) An Evaluation of Low-Cost Progression Markers in HIV-1 Seropositive Zambians. HIV Medicine, 1, 125-127. http://dx.doi.org/10.1046/j.1468-1293.2000.00016.x

[11] Phillips, A.N., Sabin, C.A., Elford, J., Bofill, M., Timms, A., Janossy, G. and Lee, C.A. (1996) Serum $\beta_{2}$-Microglobulin at HIV-1 Seroconversion as a Predictor of Severe Immunodeficiency during 10 Years of Followup. Journal of Acquired Immune Deficiency Syndromes \& Human Retrovirology, 13, 262-266. http://dx.doi.org/10.1097/00042560-199611010-00008

[12] Beck, E.J., Kupek, E.J., Gompels, M.M. and Pinching, A.J. (1996) Correlation between Total and CD4 Lymphocyte Counts in HIV Infection: Not Making the Good an Enemy of the Not So Perfect. International Journal of STD \& AIDS, 7, 422-428. http://dx.doi.org/10.1258/0956462961918392

[13] Gitura, B., Joshi, M.D., Lule, G.N. and Anzala, O. (2007) Total Lymphocyte Count as a Surrogate Marker for CD4+ T Cell Count in Initiating Antiretroviral Therapy at Kenyatta National Hospital, Nairobi. East African Medical Journal, 84, 466-472.

[14] Mbanya, D., Assah, F., Ndembi, N. and Kaptue, L. (2007) Monitoring Antiretroviral Therapy in HIV/AIDS Patients in Resource-Limited Settings: CD4 Counts or Total Lymphocyte Counts? International Journal of Infectious Diseases, 11, 157-160. http://dx.doi.org/10.1016/j.ijid.2006.02.008

[15] Akinola, N.O., Olasode, O., Adediran, I.A., Onayemi, O., Murainah, A., Irinoye, O., Elujoba, A.A. and Durosinmi, M.A. (2004) The Search for Predictor of CD4 Cell Count Continues: Total Lymphocyte Count Is Not a Substitute for CD4 Cell Count in the Management of HIV-Infected Individuals in a Resource-Limited Setting. Clinical Infectious Diseases, 39, 579-581. http://dx.doi.org/10.1086/422722 
[16] Ajayi, A.O., Ajayi, E.A. and Fasakin, K.A. (2009) CD4+ T-Lymphocytes Cell Counts in Adults with Human Immunodeficiency Virus Infection at the Medical Department of a Tertiary Health Institution in Nigeria. Annals of African Medicine, 8, 257-260. http://dx.doi.org/10.4103/1596-3519.59581

[17] Glynn, J.R., Caraël, M., Auvert, B., Kahindo, M., Chege, J., Musonda, R., Kaona, F., Buvé, A. and Study Group on the Heterogeneity of HIV Epidemics in African Cities (2001) Why Do Young Women Have a Much Higher Prevalence of HIV than Young Men? A Study in Kisumu, Kenya and Ndola, Zambia. AIDS, 15, S51-S60. http://dx.doi.org/10.1097/00002030-200108004-00006

[18] Angelo, A.L., Angelo, C.D., Torres, A.J., Ramos, A.M., Lima, M., Netto, E.M. and Brites, C. (2007) Evaluating Total Lymphocyte Counts as a Substitute for CD4 Counts in the Follow up of AIDS Patients. Brazilian Journal of Infectious Diseases, 11, 466-470. http://dx.doi.org/10.1590/S1413-86702007000500005

[19] Daka, D. and Loha, E. (2008) Relationship between Total Lymphocyte Count (TLC) and CD4 Count among Peoples Living with HIV, Southern Ethiopia: A Retrospective Evaluation. AIDS Research and Therapy, 5, 26. http://dx.doi.org/10.1186/1742-6405-5-26

[20] Balak, D.A., Bissell, K., Roseveare, C., Ram, S., Devi, R.R. and Graham, S.M. (2014) Absolute Lymphocyte Count Is Not Suitable Alternative to CD4 Count for Determining Initiation of Antiretroviral Therapy in Fiji. Journal of Tropical Medicine, 2014, Article ID: 715363. http://dx.doi.org/10.1155/2014/715363 